\title{
Ideas versus rival human capital: Industry evidence on growth models
}

\author{
Peter J. Klenow* \\ Graduate School of Business, University of Chicago, Chicago, IL 60637, USA
}

Received 2 January 1996; received in revised form 16 June 1997; accepted 5 August 1997

\begin{abstract}
Using 1959-1991 growth rates for 449 4-digit US manufacturing industries, I test 'idea' and 'rival human capital' models of endogenous growth. I find the following: First, TFP growth is faster in industries that are more intensive in capital and intermediate goods and less intensive in labor, favoring idea models over rival human capital models. Second, industries with rapidly declining prices for their capital and intermediate goods exhibit above-average TFP growth, which one would expect if improvements in variety and quality are only partially measured by output deflators: understated price declines upstream translate into higher measured TFP growth downstream. (C) 1998 Elsevier Science B.V. All rights reserved.
\end{abstract}

JEL classification: J24; L16; O3; O41

Keywords: Ideas; Human capital; Growth; Industry data

\section{Introduction}

Endogenous growth models can be crudely divided into two classes. The first class consists of 'idea' models such as Romer (1990b), Grossman and Helpman (1991), and Aghion and Howitt (1992). In these models new products or processes (ideas) spring from $R \& D$ expenditures. The new products raise productivity once they are embodied in nonlabor inputs such as higher quality or more specialized capital and intermediate goods. As Romer (1991) argues, ideas are

\footnotetext{
*E-mail: pete.klenow@gsb.uchicago.edu
} 
nonrival in that they can be embodied in many units of capital and intermediate goods without having to duplicate the upfront $R \& D$.

The second class of endogenous growth models consists of rival human capital models such as Jones and Manuelli (1990) and Rebelo (1991). By 'rival' is meant skills which accrue solely to the person investing in those skills. In Lucas (1988) human capital is not solely rival in that one worker's human capital raises the productivity of other workers. An example of purely rival human capital would be dexterity learned by experience with a manual task.

These two classes differ in the factor whose accumulation drives growth. In the first class ideas are being accumulated; in the second rival human capital is being accumulated. Of course, human capital may complement idea-driven growth. Researchers surely need human capital in order to conceive ideas. And ideas are ipso facto the nonrival human capital of their originators. Further, ideas embodied in equipment or intermediate goods are not useful if workers lack the requisite human capital to use them.

Even if human capital is necessary for generating and commercializing ideas, the positive and normative implications of these classes differ considerably. Rival human capital models point to schooling and training, and the effect of tax rates and subsidies upon them (e.g. King and Rebelo, 1990; Rebelo and Stokey, 1995). With entirely rival human capital, the decentralized equilibrium can be competitive and efficient. Idea accumulation models also tend to feature a prominent role for schooling, but additionally stress university and commercial research, knowledge spillovers, intellectual property rights, and R\&D tax policy. Because ideas are nonrival and give rise to nonconvexities, decentralized equilibria are generically inefficient in ideas models (see Romer, 1990a, 1992, 1994). Finally, as Romer (1993) argues, these two classes have dramatically different policy implications for developing countries.

Can one empirically distinguish between these two classes? The following example illustrates how industry growth data can help. Consider Rebelo's model (Rebelo, 1991) wherein rival human capital accumulation drives growth in total factor productivity (TFP). Suppose that all workers have the same amount of human capital and that human capital is general, i.e. equally valuable in all industries. In the data industries differ in their labor intensity, defined as the share of industry revenue going to labor. If these differences in labor intensity are exogenous then the Rebelo model implies that TFP growth should be higher in labor-intensive industries.

Next consider Romer's model (Romer, 1990b). In Romer's set-up TFP growth is fueled by new varieties of capital and intermediate goods. An industry intensive in such inputs (and therefore less intensive in labor) should exhibit more rapid TFP growth. This is precisely the opposite prediction from the Rebelo model. Hence the pattern of labor intensity and TFP growth across industries may shed light on the source of growth. What do the data say? Using 1959-1991 averages for each of 449 US manufacturing industries, I find that 
industries with high capital and intermediate good shares and low labor shares display more rapid productivity growth. ${ }^{1}$

Before proceeding, it is useful to consider a hybrid model wherein ideas boost productivity once they are learned and applied by workers. Examples include software commands, the quadratic formula, the Capital Asset Pricing Model, and the Black-Scholes option pricing formula. This human capital is not purely rival since it is less costly to acquire once someone has conceived of and documented it. In its policy implications, this hybrid is essentially an idea model. Funding for university $R \& D$ and textbook copyright protection are corollaries to $R \& D$ tax credits and patent protection. In its empirical implications for industries, however, this hybrid is like a rival human capital model. Specifically, the test outlined above cannot distinguish this hybrid from models with only rival human capital. What the test can do is distinguish human capital accumulation among workers from the accumulation of ideas in the form of new types of capital and intermediate goods.

The rest of the paper proceeds as follows. Section 2 documents facts about industry productivity growth, including but not confined to the factor shares just discussed. Section 3 lays out a series of growth models and sequentially checks their consistency with the facts documented in Section 2. Section 4 concludes.

\section{US industry productivity growth}

The NBER Manufacturing Productivity Database contains data on prices and quantities of output and inputs for 450 4-digit US manufacturing industries from 1958 to $1991 .^{2}$ The 4-digit industry aggregates derive from establishment data collected in the Census Bureau's Annual Survey of Manufactures and quinquennial Census of Manufactures. To investigate the long-run growth properties of the data, I look at 1959-1991 average growth rates for each variable for each industry. In the case of TFP growth, time-averaging may be particularly important to help purge the data of unmeasured cyclical changes in factor utilization.

Before proceeding, I need to decide whether to focus on gross output or value added. If gross output is Leontief in value added and materials, then value added

\footnotetext{
${ }^{1} \mathrm{R} \& \mathrm{D}$ inputs are not netted out in the construction of this TFP data. Since R\&D is believed to be labor-intensive, omitting R\&D actually helps distinguish the two models. Specifically, it avoids mixing up (a) idea generation through $\mathrm{R} \& \mathrm{D}$, with (b) human capital accumulation among those producing current output.

${ }^{2} 1972$ SIC definitions. The NBER Manufacturing Productivity Database is available via ftp at www.nber.org. See Bartelsman and Gray (1996) for documentation.
} 
Table 1

Industry TFP growth facts (gross output)

No of industries

Time period

Independent variable: TFP growth

1. Output deflator growth

Department variable: TFP Growth

2. $N$ share

3. Nonproduction $N$ share

4. High wage $N$ share

5. $K$ share

$M$ share

6. $K$ share

$M$ share

$(K$ share $) \cdot(K$ deflator growth $)$

( $M$ share $) \cdot(M$ deflator growth $)$

\section{9}

1959-91

-0.88
$(0.03)$

-1.87
$(0.66)$

$-0.89$

(1.45)

$-1.48$

(0.57)

3.45

(1.08)

1.80

(0.65)

13.6

(2.1)

6.04

(0.81)

$-2.28$

(0.45)

$-1.01$

(0.14)

$447^{\mathrm{a}}$
$1959-91$

1959-91

-0.82
$(0.03)$

$-0.72$

(0.04)

449

1959-75

449

1975-91

$-0.87$

(0.03)

$-3.24$

(0.97)

$-4.76$

(2.00)

$-4.16$

(0.86)

1.78

(1.46)

2.27

(0.95)

7.33

(2.10)

4.45

(0.95)

$-1.24$

(2.10)

$-0.74$

(0.12)

Data Source: NBER Manufacturing Productivity Database.

$N=$ labor, $K=$ capital, $M=$ nonenergy materials. OLS estimates (standard errors in parentheses). ${ }^{\mathrm{a}}$ Excludes the computer industries (SIC 3573 and SIC 3674).

is a meaningful concept. But evidence suggests that, contrary to the Leontief assumption, there is some substitutability between value added and materials. Bruno (1984) reviews a number of empirical studies and concludes that the elasticity of substitution between materials and value added is between 0.3 and 0.4. Rotemberg and Woodford (1996) argue that a reasonable value is 0.7. Based on this evidence I will emphasize results obtained with gross output data (Table 1). I also report results obtained with value added data (Table 2). ${ }^{3}$

\footnotetext{
${ }^{3}$ The fact that the elasticity of substitution is below one (the level under Cobb-Douglas) does not suggest any problem with using the gross-output-based TFP data in the NBER Database. The reason for this is that this TFP data was constructed using period-by-period factor shares as divisia weights. Diewert (1976) shows that such time-varying weights yield an excellent approximation to TFP growth for any continuous production function.
} 
Table 2

Industry TFP growth facts (value added) ${ }^{\mathrm{a}}$

No of industries
Time period
Independent variable: TFP growth
1. Output deflator growth

Dependent variable: TFP growth

2. $N$ share

3. Nonproduction $N$ share

4. High wage $N$ share

5. $K$ share

6. $K$ share

$(K$ share $) \cdot(K$ deflator growth $)$

\section{9}

1959-91

$$
\begin{array}{r}
-0.98 \\
(0.01)
\end{array}
$$

-0.96
$(0.01)$

-0.93
$(0.01)$

$-0.96$

(0.02)

$\begin{array}{lll}447^{\mathrm{b}} & 449 & 449 \\ 1959-91 & 1959-75 & 1975-91\end{array}$

$\begin{array}{cc}-11.1 & -10.4 \\ (2.5) & (2.2) \\ -7.40 & -15.0 \\ (4.93) & (4.4) \\ -14.7 & -13.3 \\ (21.4) & (21.4) \\ 11.1 & 10.4 \\ (2.5) & (2.2) \\ 27.2 & 6.46 \\ (3.9) & (4.41) \\ -3.69 & 0.90 \\ (0.72) & (0.86)\end{array}$

$\begin{array}{rc}-16.3 & -9.48 \\ (4.4) & (2.61) \\ -15.0 & -8.87 \\ (8.8) & (5.05) \\ 6.84 & -39.4 \\ (27.7) & (18.8) \\ 16.3 & 9.48 \\ (4.4) & (2.61) \\ 53.8 & 26.5 \\ (6.3) & (3.7) \\ -16.3 & -3.24 \\ (1.2) & (0.53)\end{array}$

Data Source: NBER Manufacturing Productivity Database.

$N=$ labor, $K=$ capital. OLS estimates (standard errors in parentheses).

${ }^{a}$ Observations with (real value added)/(real gross output) $<0.05$ are excluded to avoid real value added being near zero (real value added is negative for $1.5 \%$ of the observations).

${ }^{\mathrm{b}}$ Excludes the computer industries (SIC 3573 and SIC 3674).

Reassuringly, the qualitative results obtained with gross output largely hold up with value added. ${ }^{4}$

Table 1 presents results of OLS regressions involving industry TFP growth. In Section 3 these regression results will be compared to the predictions of a series of endogenous growth models. Each of the 449 4-digit industries is one observation in these regressions. ${ }^{5}$ Labor's share equals the wage bill divided by nominal gross output; material's share equals nonenergy materials purchases

\footnotetext{
${ }^{4}$ For $1.5 \%$ of the observations, real value added is actually negative. This underscores the problem with assuming no substitutability between value added and materials when some exists. To avoid big distortions in growth rates, for the value added calculations I excluded all observations for which real value added is less than $5 \%$ of real gross output. The results were not sensitive to using $3 \%$ or $7 \%$ instead.

${ }^{5}$ The NBER Database does not contain TFP data for SIC 2794, so I omit it leaving 449 industries. Also, the Database does not contain 1991 TFP for SIC 2384, so for SIC 2384 I use 1959-1990 averages.
} 


\section{9-1991 Deflator and TFP Growth}

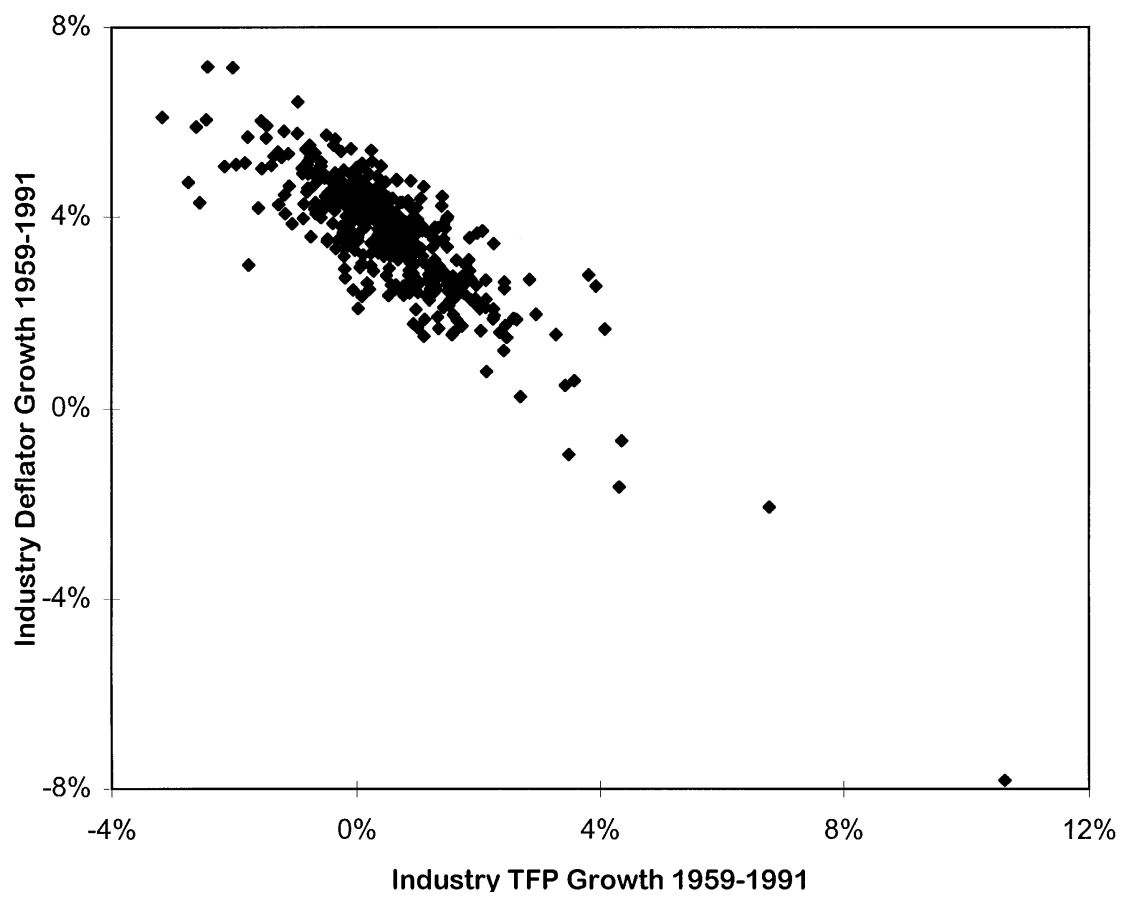

Fig. 1. 1959-1991 deflator and TFP growth.

divided by nominal gross output; capital's share is calculated as a residual (netting off energy's share as well), a valid procedure even in the presence of market power so long as pure profits are zero on average over 1959-1991 in each industry. ${ }^{6}$ Note that materials refer to all intermediate goods not just 'raw' materials; for example, semiconductors (SIC 3674) are materials inputs to the electronic computing equipment industry (SIC 3573).

Consider the first column of estimates in Table 1, which uses 1959-1991 averages and all 449 industries. Regression 1 shows that industries with 1\% faster than average TFP growth exhibit average annual relative price declines of about $0.88 \%{ }^{7}$ This fact is starkly illustrated in Fig. 1. Regressions $2-5$ involve factor shares. Industries with high labor shares exhibit slower TFP growth, with

\footnotetext{
${ }^{6}$ For the Table 2 results the labor and capital shares are in nominal value added. Likewise, the TFP data used for Table 2 was constructed using value added data.

${ }^{7}$ Fabricant (1942) and Salter (1966) find qualitatively the same for US and British manufacturing industries over 1899-1939 and 1924-1950, respectively.
} 
statistically significant results for all labor and high-wage labor, but not for nonproduction labor. ${ }^{8}$ Closely related, industries with higher capital and materials shares exhibit faster TFP growth. ${ }^{9}$ Regression 6 involves share-weighted factor price changes. Industries with rapidly declining share-weighted capital and materials prices show significantly quicker TFP growth, even controlling for their intensity in capital and materials.

Since these facts will be compared to the predictions of the two classes of endogenous growth models, it is important to know whether they are robust. Are the estimates sensitive to outliers? The computer industries - SICs 3573 (electronic computing equipment) and 3674 (semiconductors and related devices) - have by far the two highest TFP growth rates (see Fig. 1). SIC 3573 is an outlier in part because its TFP growth has been calculated using hedonic methods. Griliches (1994) expresses concern about using this industry in regressions given that hedonics have not been applied elsewhere, such as in the upstream semiconductor industry. The second column of estimates in Table 1 provides results excluding the two computer industries. The computer industries have above-average labor intensity, nonproduction labor intensity, and high wage labor intensity, so omitting them reinforces the finding that industries intensive in labor have below-average TFP growth. The computer industries also have rapidly declining capital and materials prices, so that omitting them weakens the extent to which industries with declining capital and materials prices show unusually high TFP growth. The qualitative results remain intact.

Are the estimates robust to changes in the sample period? As shown in the third column of estimates in Table 1, the 1959-1991 results on labor intensity vanish when one examines the 1959-1975 subperiod. The remaining results hold up pretty well. The fourth column shows that most of the 1959-1991 results also carry over to the 1975-1991 portion of the sample, only with lower levels of statistical significance.

Are the results consistent under different ways of calculating productivity? The TFP numbers used for Table 1 come with the NBER Database and use Solow's method with five factors: production workers, nonproduction workers, physical capital (equipment and structures), nonenergy materials, and energy. The results change little when TFP growth is instead calculated using the three factors of total hours worked, total capital, and total materials. Finally, the results were not sensitive to the way in which capital's share was calculated. When a Hall-Jorgenson rental rate of capital was applied to each industry capital stock to calculate capital's share, and when shares were constructed as

\footnotetext{
${ }^{8}$ I estimate the 'high wage labor intensity' of an industry by computing the 1959-1991 average of (relative wage) * (labor's share) in the industry.

${ }^{9}$ These shares do not sum to exactly one since energy inputs are excluded.
} 
a percentage of total costs rather than nominal gross output, the results were essentially the same as in Table $1 .^{10}$

The estimates in Table 1 are probably biased because of measurement error in the average shares and growth rates for each industry. Suppose errors are 'classical' - that is, additive, uncorrelated with the true values, and uncorrelated across industries. Such errors lend a positive bias to labor share coefficients and a negative bias to coefficients on capital and materials shares in Table 1 . The logic is as follows. Labor input grows less quickly than capital and materials for most industries. ${ }^{11}$ So an overstated industry labor share contributes to an overstatement of that industry's TFP growth. Thus classical measurement error in industry factor shares would be biased against the signs estimated in Regressions $2-5$ in Table 1.

Measurement error in the price deflators is of greater concern. It generates opposite-in-sign, equal-in-magnitude errors in TFP growth, biasing the coefficient from regressing deflator growth on TFP growth toward -1. A true coefficient of zero, however, requires that the error swamp the signal in TFP growth rates: a signal to noise ratio of 0.14 is needed to generate a coefficient of -0.88 in Table $1 .^{12}$ Deflator growth errors also positively bias the correlation between materials price changes and TFP growth: overstated materials deflator growth means understated materials input growth and therefore overstated TFP growth. The correlation between materials deflator growth and TFP growth is -0.31 ( $p$-value 0.0001 ), however, consistent with the deflators containing a good portion of signal. In summary, the Table 1 estimates are fairly robust, but are of course sensitive to nonclassical measurement error.

\section{Growth models and industry productivity growth}

How do various growth models stack up against the facts about industry productivity growth in Table 1? I consider a sequence of growth models, each with no uncertainty. Without loss of generality, each model has only two industries whose TFP growth rates are compared. The common features are as follows.

\footnotetext{
${ }^{10}$ The TFP growth rates in the NBER Database were computed with the average of current and prior year factor shares as weights on input growth. The estimates are almost the same with current year factor shares.

${ }^{11}$ Of 449 industries, the real capital stock and real materials inputs grew faster than hours worked in 426 and 431 of the industries.

${ }^{12}$ Let $g_{\mathrm{p}}=g_{\mathrm{p} *}+\varepsilon$ and $g_{\mathrm{TFP}}=g_{\mathrm{TFP} *}-\varepsilon$ where $*$ 's denote true values and $\varepsilon$ has classical properties. If the true OLS coefficient is zero, regressing $g_{\mathrm{p}}$ on $g_{\mathrm{TFP}}$ yields $\operatorname{cov}\left(g_{\mathrm{p}}, g_{\mathrm{TFP}}\right) /$ $\operatorname{var}\left(g_{\mathrm{TFP}}\right)=-\sigma_{\varepsilon}^{2} /\left(\operatorname{var}\left(g_{\mathrm{TFP} *}\right)+\sigma_{\varepsilon}^{2}\right)$. Equating this to -0.88 implies $\left(\operatorname{var}\left(g_{\mathrm{TFP} *}\right) / \sigma_{\varepsilon}^{2}=0.14\right.$.
} 
A continuum of firms produce the final good $Y$ (used for consumption, investment, and materials) by combining intermediate goods $Y_{1}$ and $Y_{2}$ :

$$
Y=C+I+M=Y_{1}^{\theta} Y_{2}^{1-\theta},
$$

with $\theta \in(0,1)$. These final good producers maximize current period profits given by

$$
\prod_{Y}=Y_{1}^{\theta} Y_{2}^{1-\theta}-p_{1} Y_{1}-p_{2} Y_{2},
$$

where $p_{1}$ and $p_{2}$ are the prices of $Y_{1}$ and $Y_{2}$ in terms of the final good $Y$, whose price at each instant is normalized to 1 . All firms take $p_{1}$ and $p_{2}$ as given. Combining the first-order conditions for final good firms' optimal choices of $Y_{1}$ and $Y_{2}$ yields the familiar Cobb-Douglas property of constant nominal output shares

$$
\frac{p_{1} Y_{1}}{p_{2} Y_{2}}=\frac{\theta}{1-\theta} \text {. }
$$

Although constant nominal output shares are quite convenient for modeling, nominal output shares are not constant in the data. The standard deviation of 1959-1991 annual growth rates of nominal shipments across the 449 manufacturing industries is $2.4 \%$. This may stem partly from nonhomotheticity of downstream preferences and technologies, as suggested by the steady decline in the share of the processed food industry over 1959-1991. The differences are correlated with TFP growth: $1 \%$ faster annual TFP growth goes along with $0.48 \%$ (s.e. $0.09 \%$ ) faster annual growth in nominal shipments (without the computer industries the coefficient is 0.37 , s.e. 0.11 ). This might be because growing markets induce faster TFP growth ${ }^{13}$ or because the elasticity of substitution between products exceeds unity. As I briefly discuss below, the assumption of constant nominal shares bears directly on the correlation between industry price and output changes, but seems otherwise innocuous for this investigation.

Each of the intermediate goods $\left(Y_{1}\right.$ and $\left.Y_{2}\right)$ is produced by a continuum of firms using human and physical capital. The models sketched below differ in the details of the intermediate goods production technology and in the accumulation technologies for human capital and ideas.

\subsection{Exogenous growth}

Intermediate goods are produced by a continuum of perfect competitors operating production technologies

$$
\begin{aligned}
& Y_{1 t}=Z_{1 t}\left(N_{1 t} H\right)^{\alpha_{1}} K_{1 t}^{\beta_{1}} M_{1 t}^{1-\alpha_{1}-\beta_{1}}, \\
& Y_{2 t}=Z_{2 t}\left(N_{2 t} H\right)^{\alpha_{2}} K_{2 t}^{\beta_{2}} M_{2 t}^{1-\alpha_{2}-\beta_{2}},
\end{aligned}
$$

\footnotetext{
${ }^{13}$ In Klenow (1996) I analyze the effects of industry scale on industry R\&D and growth in a Romerian model.
} 
where $Z$ is the exogenous level of technology, $N$ is hours worked by each worker, $H$ is the human capital stock of each worker, $K$ is the stock of physical capital, and $M$ is materials input. Note that, as in the data, industries differ in their factor intensity and input levels. The technology indices follow

$$
Z_{i t+1}=e^{\mu_{i}} Z_{i t}
$$

Thus TFP grows at the exogenous rate $\mu_{\mathrm{i}}$ in industry $i{ }^{14}$ The labor, capital and materials input markets are competitive. The market clearing conditions are $N=N_{1 t}+N_{2 t}, K_{t}=K_{1 t}+K_{2 t}$, and $M_{t}=M_{1 t}+M_{2 t}$. Since household time is solely devoted to work, human capital does not grow over time. Physical capital and materials inputs, in contrast, grow over time.

Define $g_{x}$ to be the growth rate (log first-difference) of $x$. Given the first equality in Eq. (1) and the market clearing conditions, a constant growth rate requires that $Y, \mathrm{C}, K_{1}, K_{2}, M, M_{1}$ and $M_{2}$ all grow at the same constant rate and that $N_{1}$ and $N_{2}$ be constant ( $N$ is constant by assumption). ${ }^{15}$ It then follows from the growth versions of Eqs. (2) and (3) that

$$
g_{p 2}-g_{p 1}=g_{Y 1}-g_{Y 2}=\mu_{1}-\mu_{2}+\left(\alpha_{2}-\alpha_{1}\right) g_{Y} .
$$

Suppose that labor intensity varies exogenously across industries and is uncorrelated with exogenous industry TFP growth rates $(\mu$ 's). Then $1 \%$ faster industry TFP growth should typically be accompanied by a $1 \%$ relative price decline. Moreover, we have no reason to expect TFP growth to be correlated with factor shares or factor price changes.

The first column of Table 3 compares the predictions of this exogenous growth model ' $Z$ ' to the Table 1 facts. If there were more substitutability than in the Cobb-Douglas specification in Eq. (1), the price declines would be less than proportionate and nominal output shares would rise with TFP growth, consistent with Regression 1 . The model does not accurately predict the outcomes of Regressions 2-6, however, since it does not predict low labor shares and falling share-weighted capital and materials goods prices in fast TFP growth industries.

\subsection{General human capital}

In Rebelo (1991) growth is endogenously sustainable because of constant returns to reproducible physical and human capital. Here Rebelo's model is

\footnotetext{
${ }^{14}$ In this and all subsequent models considered, factor shares do equal production elasticities. In this exogenous growth model, this means TFP $=Z$. Recall that the TFP data is constructed using time-varying input shares, so that its construction does not impose the Cobb-Douglas case of constant input shares shown in Eq. (3).

${ }^{15}$ A utility function with constant intertemporal elasticity of substitution over consumption yields such balanced growth equilibria.
} 
Table 3

Industry TFP growth theories versus the facts

Theories

\begin{tabular}{|c|c|c|c|c|c|}
\hline \multirow[b]{2}{*}{ Regressions } & \\
\hline & $Z$ & $H$ & $H_{i}$ & $A$ & $A_{i}$ \\
\hline 1. Output deflator growth & Yes & No & Yes & Yes & Yes \\
\hline 2. $N$ Share & No & No & No & Yes & Yes \\
\hline 3. Nonproduction $N$ share & No & No & No & Yes & Yes \\
\hline 4. High wage $N$ share & No & No & No & Yes & Yes \\
\hline 5. $K$ and $M$ shares & No & No & No & Yes & Yes \\
\hline 6. $K$ and $M$ deflator growth & No & No & No & No & Yes \\
\hline
\end{tabular}

Notes: For regressions, see Table 1.

$N=$ labor, $K=$ capital, $M=$ nonenergy materials. $Z=$ exogenous growth, $H=$ general human capital, $H_{i}=$ industry-specific human capital, $A=$ ideas, $A_{i}=$ industry-specific ideas.

(trivially) extended to multiple industries. Workers are homogeneous in that they have the same amount of human capital. Human capital is general in that it raises the efficiency of hours worked by the same proportion in each industry:

$$
\begin{aligned}
& Y_{1 t}=\left(N_{1 t} H_{t}\right)^{\alpha_{1}} K_{1 t}^{\beta_{1}} M_{1 t}^{1-\alpha_{1}-\beta_{1}}, \\
& Y_{2 t}=\left(N_{2 t} H_{t}\right)^{\alpha_{2}} K_{2 t}^{\beta_{2}} M_{2 t}^{1-\alpha_{2}-\beta_{2}} .
\end{aligned}
$$

Conventionally-measured productivity (the Solow residual) does not adjust for labor quality. Hence growth in human capital $H$ contributes to measured TFP growth. This model thus predicts faster TFP growth in more labor intensive industries:

$$
g_{\mathrm{TFP}_{i}}=\alpha_{i} \cdot g_{H} \cdot
$$

For each worker, human capital follows

$$
H_{t+1}=B N_{H t}^{\gamma} H_{t},
$$

where $N_{H}$ is hours devoted to accumulating $H$. Linearity in $H$ means human capital grows at a constant rate with a fixed amount of time invested in its accumulation. The labor, capital and materials markets are competitive with clearing conditions $N=N_{1 t}+N_{2 t}+N_{H t}$ (each worker's per-period endowment is $N), K_{t}=K_{1 t}+K_{2 t}$ and $M_{t}=M_{1 t}+M_{2 t}$.

Using Eq. (1) and these market-clearing conditions, constant growth rates for each variable over time imply that $Y, C, K, K_{1}, K_{2}, H, M, M_{1}$ and $M_{2}$ grow at the same rate and that $N, N_{1}, N_{2}$ and $N_{H}$ are constant. From Eq. (5) we then have $g_{Y_{1}}=g_{Y_{2}}$. Because the growth in human capital, physical capital, and materials is balanced, the growth rate of industry output is also balanced and therefore not linked to industry factor intensity. In turn, Eq. (2) tells us that the relative price of the two intermediate goods is constant over time. 
Table 3 shows how this ' $H$ ' model accords with the Table 1 regression results. The model fails to predict that output deflators for fast TFP growth industries have almost commensurately declining output deflators, as observed in Regression 1 . TFP growth driven by general human capital is paid for in higher wages, so it means no declines in industry marginal cost and price. As Eq. (6) shows, the coefficient from regressing TFP growth on labor's share should, according to this model, be the growth rate of human capital (Regression 2). The estimated coefficients in Table 1 for Regression 2 are negative, clearly at odds with this model. The model also cannot explain the results for Regressions 3-6 because of the correlation between labor's share and these other regressors. For example, since nonproduction labor's share is positively correlated with overall labor's share $(0.74, p$-value $=0.0001)$, the coefficient on the former should be positive (contrary to Regression 3). Moreover, the model gives no reason for shareweighted materials and capital goods prices to decline more rapidly in fast TFP growth industries (Regression 6) since labor's share is negatively correlated with these variables $(-0.65$ and $p$-value $=0.0001$ for each). As discussed in Section 2, classical measurement error biases Regressions 2-5 toward the predictions of this model, so such error cannot help reconcile this model with the facts.

\subsection{Industry-specific human capital}

Can heterogeneity of workers decouple industry TFP growth from industry labor intensity? If worker human capital is heterogeneous but general, industry wage growth should still follow industry TFP growth, in which case fast TFP growth industries will not display declining output deflators, contrary to Regression 1. For this reason general human capital, even with worker heterogeneity, is a non-starter. But what about industry-specific rather than general human capital? Here I consider a model of workers with heterogeneous and industry-specific human capital. There are two types of workers, skilled workers with growing human capital and unskilled workers with fixed human capital. ${ }^{16}$ These types might correspond to 'production' and 'nonproduction' workers (both of which are involved in producing current output), or to workers with a college degree and workers with only a high school degree. An unskilled worker can become skilled by paying an upfront time cost. The labor market is competitive, so there is a common wage for each worker type.

The first intermediate good, say computers or industrial chemicals, requires only skilled workers; the second intermediate good, say janitorial services, requires only unskilled workers whose unchanging human capital is normalized

\footnotetext{
${ }^{16}$ The implications that follow only require that unskilled workers have more slowly growing human capital. The extreme assumption is made for expositional clarity.
} 
to one: ${ }^{17}$

$$
\begin{aligned}
& Y_{1 t}=\left(N_{S 1 t} H_{t}\right)^{\alpha_{1}} K_{1 t}^{\beta_{1}} M_{1 t}^{1-\alpha_{1}-\beta_{1}}, \\
& Y_{2 t}=N_{U}^{\alpha_{2}} K_{2 t}^{\beta_{2}} M_{2 t}^{1-\alpha_{2}-\beta_{2}} .
\end{aligned}
$$

The hours worked by each unskilled worker are fixed since these workers spend no time accumulating human capital. In contrast, the human capital of skilled workers follows

$$
H_{t+1}=B N_{S H t}^{\gamma} H_{t} .
$$

$N_{S}$ and $N_{U}$ are the time endowments of the two types of workers, and the skilled workers divide their time between working in the first intermediate good industry and accumulating human capital $\left(N_{S}=N_{S 1}+N_{S H}\right.$ each period).

$N$ and $N_{U}$ are constant by assumption, and constant growth rates for each variable imply that $N_{S 1}$ and $N_{S H}$ do not grow and that $Y, C, K, K_{1}, K_{2}, M$, $M_{1}$ and $M_{2}$ all grow at the same rate. Unlike the previous models, this model does not have a balanced growth path in that $g_{H}>g_{Y}$, which follows from the fact that only skilled workers are accumulating human capital and they work only in the first intermediate good industry. Skilled workers are pulling overall growth along, and unskilled workers are slowing it down. Given (7) we have

$$
g_{\mathrm{TFP}_{i}}=\alpha_{i} \cdot g_{H_{i}}
$$

What happens over time to the wages of skilled versus unskilled workers? In each period intermediate good firms choose labor inputs so that

$$
\begin{aligned}
& w_{\mathrm{S} t} H_{t}=p_{1 t} \alpha_{1} Y_{1 t} / N_{\mathrm{S} 1 t}, \\
& w_{\mathrm{U} t}=p_{2 t} \alpha_{2} Y_{2 t} / N_{\mathrm{U}},
\end{aligned}
$$

where $w_{\mathrm{S}}$ is the wage per unit of skilled worker human capital, $w_{\mathrm{S}} H$ is the wage received by skilled workers, and $\mathrm{w}_{\mathrm{U}}$ is the wage received by unskilled workers. From Eq. (2) we know that nominal output grows at the same rate in both industries, and from constant growth we know that each labor input $(N)$ is constant. As a result the wages of unskilled workers rise at the same rate as those of skilled workers:

$$
g_{w_{\mathrm{u}}}=g_{w_{\mathrm{s}}}+g_{H}
$$

Equal wage growth is consistent with different rates of human capital accumulation because the wage per unit of growing human capital is falling $\left(g_{w_{\mathrm{s}}}<0\right)$. This is consistent with a skill premium in levels $\left(w_{\mathrm{S}} H>w_{\mathrm{U}}\right)$ created by a time cost of

${ }^{17}$ The implications that follow only require that one industry be more intensive in skilled workers. The extreme assumption is made for expositional clarity. 
becoming skilled; Eq. (9) implies only that the skill premium is constant in percentage terms, not that it is zero.

What is the intuition for Eq. (9)? The common rate of real wage growth is determined by the economy's average growth rate of human capital. Wage growth for unskilled workers is pulled up by the rising human capital of skilled workers; wage growth for skilled workers is dragged down by the lack of human capital accumulation among unskilled workers. Skilled workers' human capital is specific to the first intermediate good industry, so their growing human capital drives down the price of the first intermediate good. A falling relative price of the first intermediate good means a falling value of each unit of skilled worker human capital.

To confirm this intuition, we need only verify that relative prices decline in tandem with faster TFP growth. Using the growth versions of (2) and (7) we have

$$
g_{Y_{1}}-g_{Y_{2}}=\alpha_{1} g_{H}+\left(\alpha_{2}-\alpha_{1}\right) g_{Y}=g_{p_{2}}-g_{p_{2}} .
$$

When looking across industries, $g_{Y}$ is fixed. Suppose overall labor intensity varies exogenously across industries, and that it does not co-vary with industry skill intensity and therefore industry TFP growth. Under these assumptions the second equality means that industries with faster TFP growth should display corresponding relative price declines, roughly in line with Regression 1 in Table 1.

Now, Eqs. (8) and (9) imply that labor intensity need not be positively correlated with TFP growth, consistent with Regression 2. But Eq. (8) implies that skilled-labor intensity should be correlated with TFP growth because the higher the industry share of skilled workers the greater the weight on the workers with growing human capital. What does the evidence say about whether skilled-labor intensive industries show faster TFP growth? One proxy for skill is nonproduction worker status. Consistent with nonproduction workers being higher-skilled, they do earn higher wages than production workers. In the NBER Database, the nonproduction worker wage premium averaged 54\% across all industries over 1958-1991, and ranged from a low of $45 \%$ in 1982 to a high of $65 \%$ in 1991 . Nonproduction worker status is also highly correlated with educational attainment. Looking across 67 3-digit US manufacturing industries over 1979-1991, Kahn and Lim (1997) report a correlation of 0.92 between the share of compensation going to college-educated workers (estimated using the CPS) and the share going to nonproduction workers (estimated using the NBER Productivity Database). ${ }^{18}$

\footnotetext{
${ }^{18}$ Note that the nonproduction worker wage premium rises steadily from 1982 to 1991 , just as the college education premium does (see the 1997 Economic Report of the President for education premium data).
} 
With these facts as some justification, I consider the share of revenue going to nonproduction workers as a proxy for skill intensity. By Eq. (8) the coefficient from regressing TFP growth on nonproduction labor's share should be the growth rate of nonproduction workers' human capital. Regression 3 in Table 1 reveals that nonproduction worker intensive industries do not display significantly faster TFP growth, and in two cases display significantly slower TFP growth. ${ }^{19}$ And share-weighted materials and capital prices decline in fast TFP growth industries (Regression 6), the opposite of what this ' $H_{i}$ ' model predicts since these variables are negatively correlated with nonproduction labor's share $(-0.52$ and -0.47 , respectively, with $p$-values 0.0001$)$.

One could argue that nonproduction labor's share is a crude measure of an industry's skill intensity. An alternative measure is the average wage in the industry. With this motivation, Regression 4 is of TFP growth on the product of an industry's relative wage and its labor share. Industries intensive in 'high wage labor' should have faster TFP growth, but the opposite is found in three of the four cases of Regression 4 in Table 1.

Kahn and Lim (1997) also work with the NBER Productivity Database and conclude that skill-intensive industries do display faster TFP growth. They reach this outcome only after weighting each industry by its level of employment. They argue that this is justified because of heteroscedasticity: the squared residuals are negatively correlated with industry employment. But I find that, in contrast to the correlation for annual cross-sections, this correlation is positive for the low frequency (1959-1991) cross-section. For Regression 6, for example, I carry out a Breusch and Pagan (1979) LM test with a Koenkar and Basset (1982) correction and obtain a $p$-value of 0.29 for the hypothesis that employment is uncorrelated with the squared residual. If I weight each industry by the inverse of its employment, as mildly recommended by this test, I find even stronger evidence against skill intensity being correlated with TFP growth. ${ }^{20}$

\subsection{Idea accumulation}

In Romer (1990b) growth is driven by new ideas in the form of new types of equipment. I modify Romer's model slightly, splitting his final good industry

\footnotetext{
${ }^{19}$ Recall that R\&D is not included in these share calculations since the data derive from manufacturing establishments.

${ }^{20}$ Incidentally, I find a $p$-value of 0.00006 for the hypothesis that the squared TFP growth residual is uncorrelated with the 1959-1991 within-industry variance of TFP growth; i.e. the squared TFP growth residual (with TFP growth calculated as average industry TFP growth from 1959 to 1991) is larger in those industries whose TFP growth bounces around a lot over 1959 to 1991. It is as if TFP data is noiser for some industries than others. When I scale each industry by the inverse of its over-time TFP variance, I find results consistent with those in the first column of Table 1. For example, for Regression 6 I find coefficients of 6.04 (s.e. 1.88), $3.22(0.55),-1.19(0.46)$ and -0.68 (0.14) on $K$ share, $M$ share, weighted $K$ share and weighted $M$ share.
} 
into two intermediate good industries which are aggregated by Eq. (1). Since the extension is trivial, I omit many details. Each of the two intermediate goods is produced by a continuum of firms using human capital and varieties of physical capital: $^{21}$

$$
\begin{aligned}
& Y_{1}=H_{Y_{1}}^{\alpha_{1}}\left\{\int_{0}^{A} x_{1}(i)^{1-1 / \sigma} \mathrm{d} i\right\}^{\left(1-\alpha_{1}\right) /(1-1 / \sigma)}, \\
& Y_{2}=H_{Y_{2}}^{\alpha_{2}}\left\{\int_{0}^{A} x_{2}(i)^{1-1 / \sigma} \mathrm{d} i\right\}^{\left(1-\alpha_{2}\right) /(1-1 / \sigma)},
\end{aligned}
$$

where $A$ denotes the measure of capital good varieties available and $x$ the quantities of each capital good used. The varieties are imperfect substitutes $(\sigma<\infty)$, so more of them means higher productivity. All existing varieties are used by each industry. Human capital is constant.

Upstream, each capital good variety is produced by a monopolist. Each monopolist owns an exclusive production license obtained from the research firm which designed the variety. Research firms receive infinitely-lived patents on each variety they design, the stock of their designs following

$$
A_{t+1}=\delta H_{A} A_{t}
$$

where $\delta$ is a research productivity parameter. Note that human capital is an input into idea production. Note further that knowledge spillovers contribute to invention: researchers generate more new ideas the greater the stock of ideas from which to learn. Linearity in $A$ allows sustained growth with fixed research input.

Using symmetry of capital good varieties and the standard way of measuring the capital stock, we have $K_{1}=A \cdot x_{1}$ so that Eq. (10) reduces to

$$
\begin{aligned}
& Y_{1}=A^{\left(1-\alpha_{1}\right) /(\sigma-1)} H_{Y_{1}}^{\alpha_{1}} K_{1}^{1-\alpha_{1}}, \\
& Y_{2}=A^{\left(1-\alpha_{2}\right) /(\sigma-1)} H_{Y_{2}}^{\alpha_{2}} K_{2}^{1-\alpha_{2}} .
\end{aligned}
$$

Thus measured TFP growth in industry $i$ is

$$
g_{\mathrm{TFP}_{i}}=\left(1-\alpha_{i}\right) \frac{g_{A}}{\sigma-1} .
$$

This is analogous to Eq. (6) in the general human capital model, but with growth in the stock of varieties (adjusted for the substitutability of varieties, $\sigma$ ) playing the role of growth in the stock of human capital. And instead of labor's share, the

\footnotetext{
${ }^{21}$ For this and the subsequent idea model, I omit materials inputs. I have in mind that materials come in different varieties just as capital goods do, the difference merely being durability, so that the treatment of capital varieties suffices to illustrate the concepts.
} 
coefficient is capital's share. Under this model a regression of industry TFP growth on industry capital share provides an estimate of $g_{A} /(\sigma-1)$.

Constant growth rates imply that $Y, C, K, K_{1}$ and $K_{2}$ all grow at the same rate and that $H_{Y 1}, H_{Y 2}$ and $H_{A}$ are constant. Using these conditions along with Eqs. (2) and (11) we have

$$
g_{Y_{1}}-g_{Y_{2}}=\left(\alpha_{2}-\alpha_{1}\right) g_{Y}+g_{\mathrm{TFP}_{1}}-g_{\mathrm{TFP}_{2}}=g_{p_{2}}-g_{p_{1}} .
$$

When comparing industries, $g_{Y}$ is fixed. By Eq. (12) industry labor intensity should be negatively correlated with industry TFP growth. Hence industries with faster than average TFP growth should display more than proportionate relative price declines.

Table 3 shows how the predictions of this ' $A$ ' model accord with the Table 1 regression results. The positive and (economically and statistically) significant coefficients on capital and materials shares (Regression 5) are as predicted by this model, again treating material varieties as growing along with those of capital. The model also lines up qualitatively with the behavior of output deflators (Regression 1), although the model predicts more than proportionate rather than less than proportionate price declines. The model has no explanation, however, for the significant correlation between share-weighted capital and materials deflator growth and industry TFP growth. Since industries use the same inputs in this model, the model cannot explain why input deflators behave differently in different industries, much less in the systematic way observed.

\subsection{Industry-specific ideas}

The US 4-digit input-output matrix is sparse, meaning material inputs tend to be specialized to a subset of industries. In this spirit, suppose intermediate good producers operate Eq. (10) but with industry-specific $A$ 's. That is, suppose the capital goods used by the two industries do not overlap. Upstream, research firms specialize in designing capital goods for use in one of the two intermediate good industries. A research firm $\mathrm{j}$ uses one of the following research technologies:

$$
\begin{aligned}
& A_{1 t+1}=\frac{\delta_{1} H_{A_{1}}(j)}{H_{A_{1}}^{1-\gamma}} A_{1 t}, \\
& A_{2 t+1}=\frac{\delta_{2} H_{A_{2}}(j)}{H_{A_{2}}^{1-\gamma}} A_{2 t},
\end{aligned}
$$

where $\gamma<1$ incorporates diminishing returns at the research sector level, which are needed to avoid corner solutions. Research firms face constant returns 
to private scale. In Klenow (1996) I more fully characterize a version of this model. A relevant finding from that study is that better "technological opportunities' $\left(\delta_{1}>\delta_{2}\right)$ lead to more $\mathrm{R} \& \mathrm{D}$ and faster growth of varieties for an industry.

Now, if input variety in an industry is not at all reflected in the effective price of its inputs, then measured TFP growth in industry $i$ is

$$
g_{\mathrm{TFP}_{i}}=\left(1-\alpha_{i}\right) \frac{g_{A_{i}}}{\alpha-1} .
$$

The price deflators in the NBER Database are based on 4-digit producer price indices compiled by the Bureau of Labor Statistics. As Griliches (1994) stresses, these deflators incorporate some but not all improvements in variety and quality. ${ }^{22}$ If industry $i$ 's deflator measures some fraction $\omega_{i}\left(0<\omega_{i}<1\right)$ of these improvements, then instead of Eq. (13) we have

$$
g_{\mathrm{TFP}_{i}}=\left(1-\omega_{i}\right)\left(1-\alpha_{i}\right) \frac{g_{A_{i}}}{\alpha-1} .
$$

Consider an industry using many new capital and material varieties, i.e. an industry with a high $g_{A}$. Since $\omega>0$, this industry will tend to have more rapidly declining deflators for these inputs. The falling effective price contributes to higher measured real inputs but not TFP growth. Since $(1-\omega)>0$, this industry will also tend to have above-average TFP growth, as some of the variety gain is not captured in the deflators. ${ }^{23}$ In short, more rapid capital and material deflator declines should go along with faster TFP growth. This is precisely what is found in Regression $6 .^{24}$

How does this industry-specific ideas model fare against the other Table 1 facts? It provides another reason for fast TFP growth industries to have declining prices, namely declining input prices (Regression 1). The positive correlation between capital and materials shares and the share-weighted capital and materials price changes means we expect the results of Regressions 2-5. In summary, the signs of the estimated coefficients in Table 1 are

\footnotetext{
${ }^{22}$ The idea models above feature only growing variety, but have much in common with idea models that feature rising quality such as in Grossman and Helpman (1991).

${ }^{23}$ Scherer (1984) finds that industry TFP growth is somewhat correlated with 'used' R\&D, the sum of an industry's own process $R \& D$ and the product $R \& D$ carried out by upstream suppliers.

${ }^{24}$ According to this $A_{\mathrm{i}}$ model, if $\omega$ is constant across industries then only the weighted deflator growth terms should enter significantly in Regression 6. But if $\omega$ does vary across industries, as seems likely, we expect the non-weighted shares to remain positively correlated with TFP growth, as found in Regression 6. Another way of saying this is that Eq. (13) is a noisy version of Eq. (13'), leaving the share variables to pick up some of the signal.
} 
the same as those predicted by this $A_{i}$ model. This industry-specific ideas model, unlike the previous models considered, is consistent with all of the Table 1 facts. $^{25}$

\section{Conclusion}

Using the human capital I gleaned from a high school typing class, I could have typed this paper on the 1982-vintage typewriter I received for my high school graduation. Correcting spelling errors would have been a slow and tedious process. In contrast, the word processor I used allowed me to correct spelling errors with only a few commands. My knowledge of the required keystrokes surely represents human capital. But I did not need to understand the software or hardware that responded to my keystrokes. With little change in my typing human capital, the ideas embedded in my computer dramatically raised my productivity in correcting typos.

Industry evidence in the NBER Database suggests that this anecdote may be more the rule than the exception. Industries with rapid productivity growth are not intensive in overall labor, nonproduction labor, or high wage labor. I could not explain these facts with either a general or industry-specific human capital model. $^{26}$

Idea models based on Romer (1990b), in contrast, conform more closely with the aforementioned facts. These models tie industry productivity to ideas embodied in capital and materials inputs, not human capital used in production. They accurately predict that industries with fast TFP growth are intensive in capital and materials. In the first model ideas are used in all industries, in the second ideas are specialized to industries. In the data rapid TFP growth industries have rapidly declining share-weighted capital and materials prices, favoring industry-specific ideas embodied in capital and intermediate goods.

In closing, the evidence presented here is suggestive but certainly not decisive. First, the facts documented might be peculiar to US manufacturing industries. They may not extend to nonmanufacturing industries or to other countries. Second, the industry evidence marshaled is indirect. More direct evidence is

\footnotetext{
${ }^{25}$ A competing explanation of Regression 6 might be that there is a positive correlation between exogenous TFP growth and exogenous upstream TFP growth. One would then need to add capital and material's shares are also exogenously correlated with TFP growth.

${ }^{26}$ A human capital model could fail to explain industry differences in TFP growth while still explaining average TFP growth in the economy. But the lack of any correlation between industry labor share (overall or nonproduction) and industry TFP growth undermines this hypothesis. Industries with high labor shares place greater weight on human capital growth, so they should tend to exhibit faster TFP growth.
} 
needed on the contributions of human capital and idea accumulation, such as in studies of post-war US growth by Denison (1985), the Bureau of Labor Statistics (1989) and Greenwood et al. (1997), and as in the study of country growth rates by Klenow and Rodríguez-Clare (1997). ${ }^{27}$ Rival human capital accumulation and idea accumulation are not mutually exclusive and both surely contribute to growth. For positive and normative purposes, it is important to know the quantitative importance of each.

\section{Acknowledgements}

I am grateful to the National Science Foundation for financial support. I am indebted to Mark Bils, Craig Burnside, Jim Kahn, Sergio Rebelo and Andrés Rodríguez-Clare for valuable comments.

\section{References}

Aghion, P., Howitt, P., 1992. A model of growth through creative destruction. Econometrica 60, 323-351.

Bartelsman, E., Gray, W., 1996. The NBER manufacturing productivity database. National Bureau of Economic Research technical working paper no. 205.

Breusch, T., Pagan, A., 1979. A simple test for heteroscedasticity and random coefficient variation. Econometrica 47, 1287-1294.

Bruno, M., 1984. Raw materials, profits, and the productivity slowdown. Quarterly Journal of Economics 99, 1-29.

Bureau of Labor Statistics, 1989. The impact of research and development on productivity growth, Bulletin 2331 (US Government Printing Office).

Diewert, W.E., 1976. Exact and superlative index numbers. Journal of Econometrics 4, 106-171.

Fabricant, S., 1942. Employment in manufacturing, 1899-1939, National Bureau of Economic Research.

Greenwood, J., Hercowitz, Z., Krusell, P., 1997. Long-run implications of investment-specific technological change. American Economic Review 87, 342-362.

Griliches, Z., 1994. Productivity, R\&D, and the data constraint. American Economic Review 84, $1-23$.

${ }^{27}$ Denison (1985) estimated the contribution to TFP growth of rising years of schooling and experience among US workers. Bureau of Labor Statistics (1989), using private R\&D and its estimated private rate of return, assigned roughly one-third of TFP growth to idea accumulation. Since the social return to R\&D may exceed the private return due to knowledge spillovers and since much investment in new ideas (such as university research) is not included in private R\&D, the BLS estimate may be a lower bound. Based on the declining relative price of equipment, Greenwood et al. (1997) attribute $60 \%$ of labor productivity growth to idea accumulation in the from of better equipment. Klenow and Rodríguez-Clare (1997) found that about $90 \%$ of country differences in growth rates of GDP per worker over 1960-1985 could be attributed to TFP growth purged of schooling human capital. 
Grossman, G., Helpman, E., 1991. Innovation and Growth in the Global Economy, MIT Press, Cambridge.

Jones, L., Manuelli, R., 1990. A convex model of equilibrium growth. Journal of Political Economy 98, 1008-1038.

Kahn, J., Lim, J., 1997. Skilled labor-augmenting technical progress in US manufacturing. Rochester Center for Economic Research working paper no. 437.

King, R., Rebelo, S., 1990. Public policy and economic growth: developing neoclassical implications. Journal of Political Economy 98, S126-S150.

Koenkar, R., Basset, G., 1982. Robust tests for heteroscedasticity based on regression quantiles. Econometrica 50, 43-61.

Klenow, P., 1996. Industry innovation: where and why. Carnegie-Rochester Conference Series on Public Policy 44, 125-150.

Klenow, P., Rodríguez-Clare, A., 1997. The neoclassical revival in growth economics: has it gone too far?. NBER Macroeconomics Annual 1997 MIT Press, 73-114.

Lucas, R., 1988. On the mechanics of economic development. Journal of Monetary Economics 22, $3-42$.

Rebelo, S., 1991. Long-run policy analysis and long-run growth. Journal of Political Economy 99, 500-521.

Rebelo, S., Stokey, N., 1995. Growth effects of flat-rate taxes. Journal of Political Economy 103, 519-550.

Romer, P., 1990a. Are nonconvexities important for understanding growth?. American Economic Review 80, 97-103.

Romer, P., 1990b. Endogenous technological change. Journal of Political Economy 98, S71-S102.

Romer, P., 1992. Two strategies for economic development: using and producing ideas. Proceedings of the World Bank Annual Conference on Development Economics, Supplement to the World Bank Economic Review, pp. 63-91.

Romer, P., 1993. Idea gaps and object gaps in economic development. Journal of Monetary Economics 32, 543-574.

Romer, P., 1994. New goods, old theory, and the welfare costs of trade restrictions. Journal of Development Economics 43, 5-38.

Rotemberg, J., Woodford, M., 1996. Imperfect competition and the effects of energy price increases on economic activity. Journal of Money, Credit, and Banking 28, 550-577.

Salter, W.E.G., 1966. Productivity and technical change. Cambridge University Press, Cambridge.

Scherer, F.M., 1984. Using linked patent and R\&D data to measure interindustry technology flows. in: Griliches, Z. (Ed.), R\&D, patents and productivity, University of Chicago Press, pp. 417-464. 